International Journal of Chemical Engineering Research.

ISSN 0975-6442 Volume 10, Number 2 (2018), pp. 105-118

(C) Research India Publications

https://dx.doi.org/10.37622/IJChER/10.2.2018.105-118

\title{
Ion Exchangers as Catalyst in Esterification Reaction: A Review
}

\author{
Rajendra Bhaskar Bhandare \\ Chemical Engineering Department, Dr. B. A. Technological University, \\ Lonere, Tal. Mangaon, Dist. Raigad, Maharashtra, India, 402103, India,
}

\begin{abstract}
This review articles describe the use of ion exchange resins as catalyst in esterification reaction. Esterification is chemical process used for making esters. Esters are chemicals used in the flavours, fragrance, pharmaceutical and plastic industries. Different routes exist to manufacture esters but common route is homogenous acid catalyst are used. These catalyst having corrosion and pollution problems and also separation from reaction medium is difficult. To overcome these problem ion exchange resin (IER) are used as catalyst. Ion exchange is the reversible interchange of ions between a solid and a liquid in which no permanent change in structure of solid. These catalyst facilitated by recovery and recycle. Its reuse increases the productivity and cost effectiveness in esterification reactions. Due to easier workup, chemical industry has strong preference for ion exchange resin catalyst but these catalysts does not offer selectivity observed in homogenous catalyst and limitation of ion exchange resin is temperature except Nafion. These reviews discuss industrially important reactions. Various types of reactors employed for esterification reactions like batch reactors, fixed bed reactors/reactive chromatography (RC), simulated moving bed reactors has been discussed. Ion exchange catalyst moulded in different shapes which acts as catalyst and packing this can be useful in the reactive distillation (RD), which also incorporated
\end{abstract}

Key words: Esterification, Ion exchange resins, Batch reactors, Fixed bed reactors, Simulated moving bed reactors,

\section{INTRODUCTION}

The esterification reaction has a broad spectrum of uses from the preparation of highly specialized esters in the chemical laboratory to the production of millions of tons of commercial ester products. Esterification is the chemical process for 
making esters, which are compounds of the chemical structure R-COO R' where R and $\mathrm{R}^{\prime}$ are either alkyl or aryl groups. The most common method for preparing esters is to heat a carboxylic acid with an alcohol while removing the water that is formed.

Ion exchange is defined as insoluble matrix containing labile ions capable of exchanging with ions in the surrounding medium without major change in structure [1]. Ion exchange is used in water treatment, in chemical synthesis, medical research, food processing, mining, agriculture and a variety of other areas.

Acid catalyst is usually needed to make the reaction occur at a useful rate. The chemical structure of the alcohol, the acid, and the acid catalyst used in the esterification reaction all affect its rate. These differing rates of reaction were first reported by Nikolay Menschutkin in 1879 - 1883. German chemists, during World War II, developed solid acid catalysts resins for use in the manufacture of esters. These solid catalysts work well with acid sensitive esters because they can be separated from the product by filtration and therefore, the catalyst does not spend very much time in contact with the acid unstable product.

The utility of ion exchange rests with the ability to use and reuse the ion exchange material. In 1935 the introduction of synthetic organic ion exchange resins in chemical research laboratory [2]. Synthesis of phenolic condensation products containing either sulfonic or amine groups which could be used for the reversible exchange of cations or anions. The variety of functional groups have been added to the condensation or addition polymers used. Physical and chemical stability have been modified and improved. As a result of these advances, the inorganic exchangers (mineral, greensand and zeolites) have been almost completely displaced by the resinous types except for some analytical and specialized applications. In early stage develop applications with limited number of resin and later new resins are developed for new applications. As stated of the phenol formaldehyde was introduced and cation exchange was attributing to the phenolic - OH group. And then after 1960 macroporous and ultrafine resins were introduced in 1980 bifunctional ion exchange resins allowed for kinetics and biomass was used as an alternative support. From 2000 to 2008 aminophosphonte, hydroxamic acid and piperidine were developed as functional groups. Ion exchange resins having advantages like lower capital and process cost eliminating equipments and steps required to remove catalyst as required in homogenous catalysis, product yield and purity improved and it can be reused many times. Further it has disadvantages like problem of corrosion low thermal stability. Fixed bed reactors and slurry reactors can be used for esterification reactions. A reactive distillation reactor has been used for alkylation of aromatics.

The rest of the paper is organized as: Section 2 describes the different case studies of esterification reactions using ion exchange resin. And the paper is concluded in section 3 . 


\section{CASE STUDIES}

Kiss et al. studied that Tri-butyl citrate was synthesized with yields of higher than $90 \%$ after $4 \mathrm{~h}$ at $150^{\circ} \mathrm{C}$ with $12 \%$ (by weight) of a macroporous cation-exchange resin and a butanol/citric acid molar ratio of 5:1 unsaturated carboxylic acids (e.g., acrylic acid) were esterified with alcohols (e.g., 2ethylhexanol) in an ascending reactor that contained strongly acidic cation exchangers with mixing at a certain point and a recirculation loop [3].

Saha and sharma investigated the uncatalyzed and catalyzed (with cationexchange resin) esterification of formic acid and chloro acetic acid, with dicyclopentadiene (DCPD) The effect of various parameters, e.g. speed of agitation, catalyst loading, mode ratio of the reactants, temperature, concentration of formic acid in aqueous solutions were studied the reaction conditions were optimized [4].

Mazzotti et al. showed complex dynamical behavior of chromatography reactors. For this, the synthesis of ethyl acetate and water from ethanol and acetic acid on commercial polystyrene - divinylbenzene acidic resin is considered. The chromatographic reactor exhibits a rather rich dynamical behavior, which is a consequence of the dual role, as a catalyst and as a selective sorbent, played by the resin. In particular, it is characterized by the development of composition fronts traveling along the fixed bed column at well-defined propagation velocities. By interpreting the obtained results in terms of these classical nonlinear chromatography concepts, a deep insight into the dynamical behavior of the chromatographic reactor was achieved [5].

Petrini el al. worked out the methyl esterification of carboxylic acid using Amberlyst 15 as acid catalyst in methanol. It is reported that no recemizaion, epimerization or ketalization products were observed with recommended method. The results obtained were notable in the esterification of carboxylic acids [6].

Pouilloux et al. worked on the formulation of mono glycerides using glycerol and fatty acid in the presence of ion - exchange resin. From study observed that initially little swelling in the glycerol inhibits the reaction, whereas a swelling of the resin in the oleic acid, before the reaction, increases the activity and the selectivity. Absorption of fatty acid and glycerol and influences the esterification rate, It is known that in the esterification reaction water acts as inhibitor for catalyst poisoning and the thermodynamic equilibrium. It was reported that using a molecular sieve for water trap, the oleic acid conversion increases up to $90 \%$ without any change of the mono glyceride selectivity (85\%).Excess of glycerol increases the selectivity of the mono glycerides, it decreases the activity and can be reflected as a selective inhibitor [7].

Kula et al. developed the processes of esterification of the hydroxyl acid with boric acid and pyrolysis of the resultant orthoborates produced 8- nonenoic acid giving a $45 \%$ yield. Reaction with lower aliphatic alcohols in presence of Amberlyst 15 produced alkyl 8- noneates along with some amount of a cis / trans 
mixture of alkyl 7- noneates [8].

Mahajani studied the reaction of glyoxylic acid with different aliphatic alcohols in the presence of both gelular and macroporous ion exchange resins as catalysts. The alcohol reacts with both acid and aldehyde group of glyoxylic acid to form ester and the actual of the ester, respectively. It was observed that the removal of water during the reaction increases the conversion level. With increase in temperature, better selectivity was obtained towards the actual of the ester. With increase in temperature, Better selectivity was obtained towards the acetal of the ester. The kinetics of the extractive reactions (Solid - liquid - liquid mode) of aqueous solution of glyoxylic acid with 2 - ethyl hexanol was studied and a significant conversion was obtained using dilute $(5 \% \mathrm{w} / \mathrm{w})$ solution [9].

Lode et al. designed the SMBR process with the synthesis of methyl acetate, catalyzed by a suffonated poly (styrene divinyl-benzene) resin. From study of adsorption, thermodynamics and reaction kinetics, a model for reactive chromatographic column was developed. Development of Reactive simulated moving bed chromatography (SMBR) a continuous and counter - current operation combining chemical reaction and adsorptive improvement in process performance, especially for equilibrium limited reactions involving heat - sensitive products [10].

Liu W. et al. studied kinetic data on the esterification of propionic acid with $\mathrm{n}$ - butanol catalyzed by Amberlyst 15, Amberlyst 35, Amberlyst 39, and HZSM-5 pellets were measured at the temperatures from 353 to $383 \mathrm{~K}$ in a stirred batch reactor. The data indicated that the Amberlyst series resins were all effective to carry out this esterification. Because of the insignificance of the interphase and intraparticle mass-transfer resistances, a quasi-homogeneous model employing the activity of each species was used to correlate the experimental data for Amberlyst 35. A possible mechanism of this reaction was found to follow the Rideal-Eley theory in which an adsorbed and protonated propionic acid molecule reacted with an $n$-butanol molecule in the bulk. The activity-based equilibrium constant was found to increase slightly with an increase in temperature, indicating that this reaction is nearly isothermal [11].

Yadav and Thathager studied the heterogeneous catalysts, such as Indion -170 , Amberlyst - 36, Amberlyst -15 Amberlyst IRA 120, 20\% DTP/K -10 (dodecatungstophosphoric acid supported by K-10 clay) in the esterification of maleic acid with ethanol at reflux. Pseudo - homogeneous kinetic model was developed from the experimental data and activation energy was found to be 14.2 $\mathrm{kcal} / \mathrm{mol}$. Amongst these Indion - 170, Amberlyst -36 Amberlyst -15 were observed to be the most effective. [12].

Lee M. et al. studied the kinetics of the heterogeneous esterification of propionic acid with $n$ - butanol over an acidic cation-exchange resin, Amberlyst 35, was investigated. Experiments were conducted in a fixed-bed reactor at temperatures from 353.15 to $393.15 \mathrm{~K}$ and molar ratios of feed from 0.5 to 2 . The equilibrium 
conversion of propionic acid was found to increase with increasing reaction temperature and feed composition. Gas-bubble formation was observed when the reaction temperatures were higher than $373.15 \mathrm{~K}$ at atmospheric pressure. The kinetic data at temperatures from 353.15 to $373.15 \mathrm{~K}$ and mole ratio from 0.5 to 2 were correlated with the quasi-homogeneous, the Langmuir-Hinshelwood, the Eley- Rideal, and the modified Langmuir-Hinshelwood models, respectively. The Langmuir- Hinshelwood model yielded the best representation for the kinetic behavior of the liquid-solid catalytic esterification over Amberlyst 35 [13].

Toukoniitty et al. investigated esterification of propionic acid with ethyl alcohol in presence of an ion-exchange resin as a catalyst under condition of microwave dielectric heating. Experiments were carried out in a single - mode microwave loop reactor, equipped with a heating band to compare the efficiency of the conventional convective / Conductive heating and microwave dielectric heating. It was observed that the kinetic and equilibrium of this reaction were not affected by the method of heating [14].

$\mathrm{Vu}$ et al. investigated ester hydrolysis reactions by chromatography reactor using equilibrium theory and rate model. First, the extended equilibrium theory approach was introduced as a useful tool to study the feasibility of chromatographic reactors. Application is demonstrated for systems with reactions of the type $2 \mathrm{~A} \leftrightarrow \mathrm{B}+\mathrm{C}$ or $\mathrm{A} \leftrightarrow \mathrm{B}+\mathrm{C}$, respectively. It was shown that the difference in stoichiometry has strong consequences for the feasibility. Namely, for the first reaction, total conversion and total separation was only possible if the reactant has intermediate adsorptivity. In contrast to this, for the second reaction, total conversion and total separation is always possible for any order of adsorptivities, provided that the chromatographic column is sufficiently long. Ester hydrolysis reactions with water in excess are considered as a practical application for the second type of reaction. Afterward, the column length required for total conversion and total separation is estimated using a rate based model, which takes into account the finite reaction kinetics and axial dispersion. The theoretical predictions were finally confirmed by the experimental results by using heterogeneously catalysed hydrolysis of methyl formate and methyl acetate with DOWEX 50W-X8 [15].

Erdem et al. studied kinetics of esterification of propionic acid with $\mathrm{n}$ - amyl alcohol in the presence of cation exchange resins. Esterifications of $\mathrm{n}$ amyl alcohol with propionic acid catalyzed by Amberlyst - 15 and Dowex $50 \mathrm{~W}$ and Amberlite IR-120 polymeric ion-exchange resins were carried out between 333 - 348 K. Amberlyst-15 was observed to be the most effective catalyst with respect to rate constants, but after drying it became the less effective one. The reaction rate increased with increase in catalyst concentration and reaction temperature. Stirrer speed and different mesh sizes had virtually no effect on the rate under the experimental conditions. The effect of divinylbenzene content was examined for the microporous resin Dowex 50W, and the results showed that the propionic acid conversion decreased as the divinylbenzene content was increased. 
The rate data were correlated with a second-order homogeneous reaction model [16].

Strohleina et al. studied the esterification of acrylic acid with methanol using Amberlyst 15 as a stationary phase has been investigated using a chromatographic reactor. Classical model including lumped kinetics, a linear driving force transport model and a heterogeneous kinetic model for the catalytic reaction has been developed. The additional dispersion of concentration fronts due to density gradient effects has been accounted for in the model. The model parameters have been determined directly fitting the batch column experiments. Based on the detailed batch column model, a complete model of a simulated moving bed reactor has been implemented and its optimal point of operation for the synthesis of methyl acrylate from acrylic acid has been determined [17]

Liu et al. reported an investigation into the impact of carboxylic acid chain length on the kinetics of liquid phase acid catalyzed esterification. Sulfuric acid and Nafion/silica composite solid acid catalyst (SAC -13) was used. Initial rate measured for the reactions of a series of linear chain carboxylic acids (acetic, propionic, butyric, hexanoic, and caprylic acid) with methanol at $60^{\circ} \mathrm{C}$. It was found that reaction rate decreased as the number of carbons in the linear alkyl chain increased for both sulphuric acid and SAC - 13. Using kinetic model, the reaction kinetic parameters of SAC - 13 catalysis were determined and compared for different carboxylic acids. Important parameters, such as water deactivation, catalyst reusability, and regeneration, were also affected by the size of the carboxylic acid used [18].

Alime and Hosgun worked on the esterification of propionic acid with isobutanol in the presence of Amberlyst -15 as a catalyst. Isobutyl propionate used in the food industry. Experiments were conducted in a stirred batch reactor. A solvent, 1, 4 dioxan was used. The effects of the amount of catalyst used, the reaction time, the stirring speed, and the reaction temperature on the synthesis of isobutyl were investigated [19].

Mahajan et al. proposed the recovery of trifluoroacertic acid (TFA) from its dilute aqueous solutions. Esterification with 2- propanol was carried out for recovery ( $\mathrm{T}-63$, a cation-exchange resin),. The work showed the feasibility of reactive distillation (RD) to recover TFA by esterification with 2 - propanol. Various experiments were performed using reactive distillation in batch and continuous modes; the conversion obtained is quite lower in batch experiments and significantly increased in reactive distillation to $58 \%$ for $1.4: 1$ molar ratio of IPA to TFA, Substantial recovery of TFA Achieved [20].

$\mathrm{Ju}$ et al. studied the esterification of butyric acid with $\mathrm{n}$ - butanol over Dowex 50Wx8 - 400. Experiments were performed in a reactive distillation mode, in which the water is eliminated to prevent the reverse reaction from taking place. The experimental parameters are reaction temperatures $\left(100-110^{0} \mathrm{C}\right)$, molar ratios of reactants (butyric acid/n-butanol ,0.25 - 4) and catalyst loading (10 - $40 \mathrm{~g} / \mathrm{L})$, 
and effect on the reaction rate was found that the conversion increased with temperature and catalyst loading whereas it decreased as the molar ratio of reactants increased. The rate equations were derived on the basis of the pseudohomogeneous (PH) model, Langmuir-Hinshelwood (LH) model and Eley - Rideal (ER) model. From the models showing good correlation between experimental and simulation results, the surface reaction was determined to be the rate determining step, while competitive adsorption on a catalyst surface and weak interaction between resin and water (byproduct) were confirmed in the esterification reaction of butyric acid with $\mathrm{n}$ - butanol [21].

Konwar et al. studied reaction kinetics with simultaneous esterification and transesterificaiton of acidic oils over a mesoporous sulphonated carbon catalyst. Batch reactor system was used and synthesized carbon catalyst characterized by $\mathrm{N}_{2}$ physisorption, transmission electron microscopy, and elemental analysis. A second order pseudo- homogeneous kinetic model was obtained was obtained for three different feedstock oils with 98\% accuracy. The reaction steps were kinetic controlled and not limited by inter particle diffusion or external mass transfer limitations. The loss of activity upon catalyst reuse, a deactivation model was also proposed which explained our results with 94\% accuracy. The optimized reaction conditions $\left(120^{\circ} \mathrm{C}\right.$ and $20: 1$ methanol- to- final biodiesel molar ration), yields up to $79-91$ wt. \% was achieved [22].

Diaz et al. tudied the esterification of propionic acid with 1-propanol to produce n-propyl propionate in a conventional reactive distillation column using the surface - sulfonated catalyst Amberlyst 46 immobilized in the structured catalytic packing Katapak. The influence of operating parameters, such as: reflux ratio, molar feed ratio of 1-propanol to propionic acid, distillate-to-feed ratio, and the total feed of reactants was analyzed from the results of six actual and two simulated experiments. The results show that when the reflux ratio is increased (from 2 to 2.5), the $\mathrm{n}$ - propanol concentration increases and the purity of the propyl propionate product at the column bottom diminishes, although the ester mass production rate is unaffected. The use lower molar feed ratio (2.0) yields greater $\mathrm{n}$ - propyl propionate purity at bottom and higher mass production rate. The analysis of the experimental and simulated results showed that, in a conventional RDC, at a reflux ratio of 2.0 , total feed of $4 \mathrm{~kg} / \mathrm{h}$, and a molar feed ratio of 2.0, the n-propyl propionate production rate was highest as was the propyl alcohol recovery. However, at the same conditions and total feed of $3.0 \mathrm{~kg} / \mathrm{h}$, the bottoms n-propyl propionate purity was highest and only a binary mixture was formed [23].

Singh et al. investigated the esterification reaction of butyric acid with ethanol in the presence of ion exchange resin Amberlyst 15. The kinetics of esterification of butyric acid with ethanol in the temperature ranging between $328.15 \mathrm{~K}$ and $348.15 \mathrm{~K}$ and at molar ratio 1: 5 to $1: 15$ is investigated experimentally in a stirred batch reactor using Amberlyst 15. It has also been observed that the initial reaction rate increases linearly with acid and alcohol concentrations. Rate of 
reaction is found to increase with the increase in catalyst loading, temperature, and molar ratio. Eley - Rideal model is applied to study the kinetics of the reaction. As a result, it is concluded that the acidic resin, Amberlyst 15, is a suitable catalyst for this reaction, since in the presence of it, the reaction has been found to take place between an adsorbed alcohol molecule and a molecule of acid in the bulk phase (Eley - Rideal model). It is also observed that water has inhibiting effect of reaction. Temperature dependency of the kinetic constants has been found to apply Arrhenius equation [24].

Levya et al. studied esterification of propionic acid with isoamyl alcohol using Amberlyst 70 ion exchange resin as catalyst. Experiments were performed in batch reactor at different acid to alcohol molar ratios, reaction temperatures $(353.15,373.15$, and $393.15 \mathrm{~K})$, and catalyst loadings $(8.0,4.0$, and $0.8 \mathrm{wt} \% \mathrm{of} \mathrm{kg}$ of cat $/ \mathrm{kg}$ of soln). Data obtained from experiments regressed with pseudohomogeneous and heterogeneous reaction models based upon mole fractions and NRTL activities. Models obtained fit esterification kinetics and can be used in simulation of reaction and reactive distillation processes to produce isoamyl propionate [25].

Pappu et al. investigated esterification of butyric acid kinetics over Amberlyst solid acid catalysts and the effect of alcohol carbon chain length. The liquid phase esterification of butyric acid with a series of linear and branched alcohols is examined. Four strong cation exchange resins, Amberlyst 15, Amberlyst 36, Amberlyst BD 20, and Amberlyst 70, were used along with para - toluenesulfonic acid as a homogeneous catalyst. The effect of increasing alcohol carbon chain length and branching on esterification rate at $60^{\circ} \mathrm{C}$ is presented. For all catalysts, the decrease in turnover frequency (TOF) with increasing carbon chain length of the alcohol is described in terms of steric hindrance, alcohol polarity, and hydroxyl group concentration. The kinetics of butyric acid esterification with 2 ethylhexanol using Amberlyst 70 catalyst is described with an activity-based, pseudo-homogeneous kinetic model that includes autocatalysis by butyric acid [26].

Santhanakrishnan et al. studied kinetics of mixed ethanol $/ \mathrm{n}$ - butanol esterification of butyric acid with Amberlyst 70 and $p$ - toluene sulfonic acid. Batch reactions at different temperatures and catalyst loadings, and then esterification in ethanol $/ \mathrm{n}$ - butanol mixtures of varying concentration ratios was characterized. kinetic models were developed for linear and nonlinear solutions. These models accurately predict the esterification of butyric acid by the individual alcohols. When solution density is included in the kinetic rate expression to account for the actual concentration of - $\mathrm{OH}$ groups in ethanol and $\mathrm{n}$ - butanol, butyric acid esterification kinetics with the two alcohols are described by a common rate constant. This rate constant also predicts butyric acid esterification kinetics with other alcohol combinations. The results provide significant predictive capabilities for simulating processes such as reactive distillation processes for mixed alcohol esterification [27]. 
Dange et al. studied the esterification of butyric acid with methanol in presence of acidic ion exchange resin as catalyst. Rate of butyric acid esterification with methanol increases with an increase in temperature over the range of study (323 $343 \mathrm{~K}$ ); passes through maximum with increasing alcohol to acid ratio (1- 4), increases with an increase in catalyst loading $(0-8.5 \% \mathrm{w} / \mathrm{w})$. The conversion of butyric acid was decrease in the presence of added water due to inhibiting effect of water. The maximum conversion of $94.5 \%$ was observed at optimum reaction conditions. Thus, the ion exchange catalyst was found to be very effective for the methyl butyrate synthesis. The LHHW Dual Site (considering reactants and products adsorbed on catalyst surface) heterogeneous model could be successfully applied for representing esterification kinetics for the reaction between butyric acid and methanol28].

Wang et al studied a $\mathrm{ZnCl}_{2}$ - modified ion exchange resin as the catalyst for bisphenol - A synthesis. Scanning electron microscope (SEM), Fourier transforms infrared spectrophotometer (FT-IR), thermo gravimetric analyzer (TGA) and pyridine adsorbed IR were employed to characterize the catalyst. From study it was observe that modified catalyst showed high acidity and good thermal stability. $\mathrm{Zn}_{2+}$ coordinated with a sulfonic acid group to form a stable active site, which effectively decreased the deactivation caused by the degradation of sulfonic acid. Thus the prepared catalyst exhibited excellent catalytic activity, selectivity and stability compared to the unmodified counterpart [29].

Sharma et al studied methyl pentanoate, commonly known as methyl valerate, is the methyl ester of pentanoic acid (valeric acid) with a fruity odour. In the study, kinetics of esterification of pentanoic acid with methanol catalyzed by heterogeneous catalyst in a batch-type reactor was reported. The effect of reaction conditions such as temperature, molar ratio, catalyst loading, and initial concentration of pentanoic acid and methanol, and the inhibiting effect of water on the kinetics have been studied. The pentanoic acid conversion reached $93 \%$ at $333.15 \mathrm{~K}$ at a methanol to pentanoic acid molar ratio of $10: 1$ with $7 \%(\mathrm{~g} / \mathrm{l})$ Amberlyst 15 as catalyst. Mass transfer effects were found to be negligible. EleyRideal (ER) model were fitted [30].

Ghodke et al. (2015), studied comparison of reactive distillation and reactive chromatography stabilization of bio-oil, obtained from pyrolysis of wood. Bio-oil, along with several oxygenated organic compounds, contains substantial amounts of carboxylic acids (e.g., acetic acid, $5-10 \%$ ). The ability of multifunctional reactor for stabilization of bio - oil through esterification of acid with suitable alcohol in the presence of ion-exchange resin catalyst. Reactive distillation is performed at higher a temperature which is dictated by the bubble point of the mixture, reactive chromatography allows one to perform reaction at relatively low temperatures and with lower alcohols. The main limitation of the catalyst used for esterification also catalyzes simultaneous polymerization of furfural-like components which deactivate the catalyst. Deactivation of Amberlyst-15 with ethanol after $20 \mathrm{~h}$ of continuous run in a fixed bed chromatographic-reactor was 
found to be less compared to RD [31].

Leyva et al. studied the production of isoamyl propionate by esterification of propionic acid with isoamyl alcohol, via continuous reactive distillation. The process was modeled using an equilibrium-stage approach and simulated with Aspen Plus 7.3. Experimental evaluation of the process was carried out in a $8 \mathrm{~cm}$ ID $6 \mathrm{~m}$ tall pilot-scale glass reactive - column, using Amberlyst 70 ion exchange resin as catalyst contained in a KATAPAK ${ }^{@}$ SP-11 structured packing. For a single equimolar feed, propionic acid conversions over $96 \%$ and isoamyl propionate purities over 98 wt. \% in the bottoms product were obtained. Results obtained in this work can be used for scale-up studies of an industrial reactive distillation operation [32].

Dange et al. studied the ultrasound assisted esterification of butyric acid with methanol in an ultrasound irradiated isothermal batch reactor using Amberlyst - 15 as a catalyst. Effect of parameters, temperature $(323$ - $353 \mathrm{~K})$, catalyst loading (0$8.5 \% \mathrm{w} / \mathrm{w})$, alcohol to acid ratio $(2-6)$, ultrasound power $(0-145 \mathrm{~W})$, duty cycle $(0-85 \%)$ and amount of molecular sieves added $(0-11 \% \mathrm{w} / \mathrm{w})$ on the rate of reaction was studied. Conversion of $94 \%$ was obtained in 120 minutes in presence of ultrasound. Data were correlated by using Eley - Rideal, and Langmuir Hinshelwood Hougen Watson Models taking into account reverse reaction. Studies showed that single site LHHW with reactants and products both adsorbing on catalyst surface was most suited for the obtained experimental data [33].

Bamunusingha et al. investigated esterification of acetic acid with ethyl alcohol in the presence of a cation exchange resin (Lewatit S1467). The catalyst pretreated with $\mathrm{HCl}$ showed higher acetic acid conversions. The acidic cation exchange resin treated with $\mathrm{HCl}$ was examined for catalyst loading, reaction temperature and reusability. The highest acetic acid conversion of $58 \%$ was observed for acetic acid to ethanol mole ratio of $1: 1$ at $335 \mathrm{~K}$ with a $5.4 \%(\mathrm{w} / \mathrm{w})$ catalyst loading. The experimental data were fitted with the pseudo homogeneous model, and the heterogeneous models Langmuir-Hinshelwood (LH) and EleyRideal (ER). LH model provided a better agreement with the experimental kinetic data [34].

\section{CONCLUSION}

The review has attempted to cover esterification reaction by using ion exchange resins as catalyst. This catalyst has been shown several advantages as compared to the use of homogeneous catalysts like better economics, low environmental effect. Ion exchange resin catalyst has been successfully used in batch reactor, reactive distillation and reactive chromatography.

Limitation of ion exchange resins is the temperature limit which is typically below $120^{\circ} \mathrm{C}$. but now a days catalyst like Nafion can go up to about $200^{\circ} \mathrm{C}$. Cost of Nafion is high as compared to other catalyst. The demand for environmentally friendly processes, with less energy consumption, and the 
various types ion exchange resins give them direct advantages in any competition with homogeneous catalysts.

This review indicates there is need of efforts in this field.

\section{Abbreviations}

IER- ion exchange resin

RC - $\quad$ reactive chromatography

RD - $\quad$ reactive distillation

PH- Pseudo - homogeneous

ER- $\quad$ Eley - Rideal

LH- Langmuir-Hinshelwood

PP- Popken

LHHW- $\quad$ Langmuir-Hinshelwood - Hougen - Watson

\section{REFERENCES}

[1] Chakrabarti A., Sharma M., 1993, "Cationic ion exchange resins as catalyst", Rea. Poly., 20, pp. 1 - 45

[2] Abrams I., Millar J., 1997, "A history of the origin and development of macroporous ion exchange resins", Reac. Fuct. Poly, 35, pp. 7- 22.

[3] Kiss M., Losonczi, B. Morgos, J., Rusznak, I., Haklits, I., 1980, "Study of Alkylating reaction catalyzed by cation - exchange resin”, J.chro., 201 , pp. $383-389$.

[4] Saha B. and Sharma M.M., "Reaction of dicylopentadiene with formic acid and chloroacetic acid with or without cation - exchange resin as catalysts", Rea. Fuc. Poly, 34, pp.167- 173.

[5] Mazzotti M., B. Neri, D. Gelosa, and M. Morbidelli, 1997, "Dynamics of a Chromatographic Reactor: Esterification Catalyzed by Acidic Resins", Ind. Eng. Chem. Res., 36, pp. 3163 - 3172

[6] Petrini M., Ballini R. and Marcantoni E., 1988, “Amberlyst 15: a practical, mild and selective catalyst for methyl esterification of carboxylic acids, Syn. Comm.”, 18, pp. 847- 853 .

[7] Pouilloux Y., Abro S., Vanhove C. and Barrault, 1999, "Reaction of glycerol with fatty acids in the presence of ion - exchange resins Preparation of mono glycerides", J. Mol. Cat. A: Chem., 149, pp. 243 254 ,

[8] Kula J. , Smigielski K., Quang T.B., Grzelak I., Sikora M. 1999, 
"Preparation of $\omega$ - Hydroxynonanoic acid and its esters derivatives", J. of Ame. oil Chem. Soc., 76, pp. 811- 817

[9] Mahajani S.M, 2000, "Reactions of glyoxylic acid with aliphatic alcohols using cationic exchange resins as catelysts", Rea. Fun.Pol., 43, pp. 253268.

[10] Lode F., M. Houmard, C. Migliorini, M. Mazzotti, M. Morbidelli, 2001, "Continuous reactive chromatography", Chem. Eng. Sci., 56, pp. 269 291.

[11] Liu w. Tan C., 2001, "Liquid-Phase Esterification of Propionic Acid with n-Butanol", Ind. Eng. Chem. Res., 40, pp. 3281-3286.

[12] Yadav G., Thathagar M., 2002, "Esterification of maleic acid with ethanol over cation - exchange resin catalysts", Rea. Fun. Pol., 52, pp. 99 -110.

[13] Lee M. , Chin J. , Lin H., 2002, "Kinetics of catalytic esterification of propionic acid and n butanol alcohol over Amberlyst 35", Ind. Eng. Chem. Res., 41, pp. 2882 - 2887.

[14] Toukoniitty B., Mikkola J., Eranen K., Salmi T., Murzin D., 2005, "Esterification of propionic acid under microwave irradiation over an ion exchange resin", Cat. Tod., 100, pp. 431-435,

[15] Vu T., Morgenstern A., Gruner S., Kienle A., 2005, "Analysis of Ester Hydrolysis Reactions in a Chromatographic Reactor Using Equilibrium Theory and a Rate Model”, Ind. Eng. Chem. Res., 44, pp. 9565 - 9574.

[16] Erdem, B., Cebe, M., 2006, “ Kinetics of esterification propionic acid with $\mathrm{n}$ - amyl alcohol in the presence of cation exchange resins", Kor. J. Chem. Eng., 23, pp. 896 - 901,

[17] Strohleina G., Assunçao Y., Dube N., Bardowc A., Mazzottid M., Morbidellia M., 2006,"Esterification of acrylic acid with methanol by reactive chromatography: Experiments and Simulations", Chem. Eng. Sci., 61, pp. 5296- 5306.

[18] Liu Y., Lotero E., Goodwin J., 2006, "Effect of carbon chain length on esterification of Carboxylic acids with methanol using acid catalysis", J. Cat., 24, pp. 221- 228.

[19] Alime I and Hosgun H.L, 2007, "Kinetics of synthesis of Isobutyl Propionate over Amberlyst - 15", Tur. J Chem, 31, pp. 493 - 499.

[20] Mahajan Y., Shah A., Kamath R., Salve N., Mahajani S., 2008, "Recovery of trifluoroacetic acid from dilute aqueous solutions by reactive distillation”, Sep. Pur. Tech., 59, pp. 58 - 66.

[21] Ju I., Lim H., Jeon W., Suh D., Park M., Suh Y., 2011, "Kinetic study of catalytic esterification of butyric acid and $\mathrm{n}$ - butanol over Dowex 50Wx8400”, Chem. Eng. Jou., 168 (1), pp. 293- 302. 
[22] Konwar J., Warana J., Kumar N. and Mikkola J.P., 2016, "Reaction kinetics with catalyst deactivation in simultaneous esterification and transesterification of acid oils to biodiesel (FAME) over a mesoporous sulphonated carbon catalyst", Fuel, 166, pp.1-11.

[23] Diaz M., Buchaly C., Kreis P., Pérez-Cisneros E., Lobo-Oehmichen R., Górakc A., 2012, "Synthesis of n-propyl propionate in a pilot-plant reactive distillation column: Experimental study and simulation", Com. Chem.Eng., 39, pp. $118-128$.

[24] Singh N., Kumar R., Sachan P., 2013, "Kinetic study of catalytic esterification of butyric acid and ethanol over Amberlyst 15", ISRN chem. Engg. , pp.1- 6 .

[25] Leyva F., A. Orjuela, A. Kolah, C. Lira, D. Miller, G. Rodríguez, 2013, "Kinetics of Propionic Acid and Isoamyl Alcohol Liquid Esterification with Amberlyst 70 as Catalyst", , Ind. Eng. Chem. Res., 52, pp.18153 18161.

[26] Pappu V., Kanyi V., Santhanakrishnan A., Lira C., Miller D., 2013, "Butyric acid esterification kinetic over Amberlyst solid catalysis: The effect of alcohol carbon chain length", Bio. Tech., 130, pp. 793 - 797.

[27] Santhanakrishnan A, Shannon A., Peereboom L, Lira C., Miller D., 2013 Kinetics of Mixed Ethanol/n - Butanol Esterification of Butyric Acid with Amberlyst 70 and p - Toluene Sulfonic Acid, Ind. Eng. Chem. Res., 52, pp. 1845 - 1853,

[28] Dange P., Sharam A., Rathod V., 2014, "Synthesis of Methyl Butyrate Using Heterogeneous Catalyst:Kinetic Studies", cat. Let. 144, pp. 1537 1546.

[29] Wang B., Dong J., Chen S., Wang Li , Zhu J., 2014, “ZnCl2-modified ion exchange resin as an efficient catalyst for the bisphenol - A production", Chine. Chem. Lett., 25(11), pp. 1423 - 1427.

[30] Sharma M., Toor A, and Wanchooa R, 2014, Kinetics of the Esterification Reaction between Pentanoic Acid and Methanol Catalyzed by Noncorrosive Cation Exchange Resin, Chem. Bioch. Eng. Qua. 28 (1), pp. 79 - 85 .

[31] Ghodke P., Ch V.L., A. Ganesha, S. Mahajani, 2015, "Stabilization of pyrolysis oil:Comparison of reactive distillation and reactive chromatography", Chem. Eng. Proc., 95, pp. 327 - 338.

[32] Leyva F., A. Orjuela, A. Kolah, C. Lira, D. Miller, G. Rodríguez, 2015, "Isoamyl propionate production by reactive distillation", Sep. Pur. Tech., 146, pp. $199-212$.

[33] Dange P.N., Rathod V.K., Kulkarni A.V., 2015, "Ultrasound assisted Synthesis of Methyl Butyrate Using Heterogeneous catalyst", Ult. Son., 
26, pp. 257 - 264.

[34] Bamunusingha B., De Silva E., Gunasekera M., 2016, "Performance of ion exchange resin as solid catalyst for the esterification of acetic acid with ethanol”, J. Nat. Sci, Fou., 44 (1), pp. 83 - 93. 